\title{
Endophytic Fungi Isolated from Crocus sativus L. (Saffron) as a Source of Bioactive Secondary Metabolites
}

\author{
Imane Chamkhi", Laila Sbabou, Jamal Aurag
}

\section{Imane Chamkhi', Laila Sbabou, Jamal Aurag}

Microbiology and Molecular Biology Team, Center of Plant and Microbial Biotechnology, Biodiversity and Environment. Faculty of Sciences, Mohammed V University in Rabat, MOROCCO.

\section{Correspondence}

\section{Imane Chamkhi}

Center of Plant and Microbial Biotechnology, Biodiversity and Environment. Faculty of Sciences, Mohammed V University in Rabat, Avenue IbnBattouta, BP 1014, Rabat 10000, MOROCCO.

Phone no : 212631809913

E-mail: chamkhi.imane@gmail.com

\section{History}

- Submission Date: 10-05-2018;

- Review completed: 22-06-2018;

- Accepted Date: 23-07-2018

\section{DOI : 10.5530/pj.2018.6.195}

Article Available online http://www.phcogj.com/v10/i6

\section{Copyright}

(C) 2018 Phcog.Net. This is an openaccess article distributed under the terms of the Creative Commons Attribution 4.0 International license.

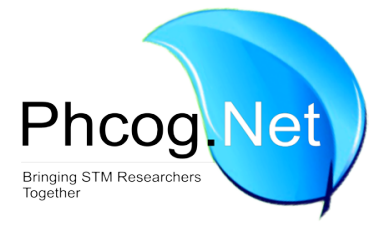

\begin{abstract}
Introduction: Endophytic fungi are becoming an important source of new natural bioactive products. Many interesting endophytic fungi have been isolated from traditional medicinal plants. Crocus sativus L. (saffron) is one of the most expensive and rarest spices in the world, used as a dye, aroma and for medicinal purposes. This study reports on the molecular characterization of endophytic fungi isolated from roots of saffron plants growing in TaliouineMorocco, and the examination of the antibacterial and antioxidant activities of secondary metabolites extracted from these endophytes. Methods and Material: The fungi were isolated from sterilized saffron root fragments and identified using internal transcribed spacer (ITS) rRNA gene sequence analysis. Three endophytes were fermented and extracted with ethyl acetate (EtOAc) and chloroform $\left(\mathrm{CHCl}_{3}\right)$. The antibacterial activity of fungi extracts was evaluated using the Agar Diffusion Method against six strains, Bacillus sp., Stenotrophomonas sp., Pseudomonas putida, Pantoea sp., Luteibacter sp. and Escherichia coli. The antioxidant activity was tested by using the $\alpha, \alpha$-diphenyl- $\beta$-picrylhydrazyl (DPPH) analysis and $\beta$-Carotene bleaching test (BCBT) methods. Results: Sixty fungal isolates were recovered and purified from saffron roots. ITS rDNA sequences were $99-100 \%$ identical to three different species: Rhizopus oryzae, Aspergillus fumigatiaffinis and Aspergillus niger. Both Rhizopus oryzae extracts had high antibacterial activity against most of the bacteria tested, while Aspergillus niger and Rhizopus oryzae extracts showed an antioxidant capacity using DPPH and BCBT methods, respectively. Conclusion: The fungal endophytes inhabiting saffron roots could be a potential source of natural plant bioactive secondary metabolites especially for antibacterial and antioxidant purposes.

Key words: Crocus sativus L., Endophytic fungi, ITS rDNA, Secondary metabolites, Antibacterial activity, Antioxidant activity.
\end{abstract}

\section{INTRODUCTION}

Endophytic fungi are microorganisms that live in the intercellular spaces of stems, petioles, roots, and leaves of plants. ${ }^{1}$ These endophytes colonize plants internally without apparent adverse effects and they are not considered as saprophytes since they are associated with living tissues without causing any noticeable symptoms of a disease. However, some endophytic fungi may become pathogenic under stressful conditions. ${ }^{2}$ Endophytic fungi have been detected in hundreds of plants including many important agricultural commodities. ${ }^{3}$ Different studies demonstrated that they produce a large number of interesting secondary metabolites including anti-cancer, antifungal, antidiabetic and immune-suppressant compounds comparable to those produced by host plants. The production of these interesting compounds makes endophytic fungi an alternative and natural source of important plant secondary metabolites. ${ }^{4}$ In addition, fungal endophytes could be beneficial to host plants by increasing their tolerance to biotic and abiotic stress factors. ${ }^{5}$ Many endophytes have the potential to synthesize various bioactive metabolites that may directly or indirectly be used as therapeutic agents against numerous diseases, such as paclitaxel, podophyllotoxin, hypericin, vinblastine, camptothecine and diosgenin which are also produced by their host. ${ }^{6}$ The production of bioactive compounds by endophytes, especially those exclusive to their host plants, are highly important from ecological, biochemical and molecular perspective.

Investigations concerning 29 medicinal plant species and 1.160 fungal endophytes showed the existence of high biodiversity, host recurrence, tissue specificity, and spatial heterogeneity. ${ }^{7}$ Some phenolic compounds were found to more likely coexist with certain endophytic fungi in the same plants, and their systematic investigation revealed that traditional medicinal plants are a rich and reliable source of novel endophytic fungi. This information has led us to assume that saffron could constitute another source of endophytic fungi with biological activity. 
Saffron is a perennial crop culture that belongs to the large family of Iridaceae and to the genus Crocus which includes about 162 species (National Center for Biotechnology Information). Crocus sativus represents the most interesting species because of the natural coloring, bitterness and aromatic power of its dried stigmas. ${ }^{8}$ The saffron have been used as a dye in cosmetics and perfumes, as spice in food and also as medicinal plant, with a potent chemotherapeutic effect for the treatment of various diseases. ${ }^{9}$ Saffron is cultivated under different climates in different countries of Asia and the Mediterranean basin. Iran is the main producer of saffron, accounting for more than $90 \%$ of world producyion, followed by India (5\%) and countries of the Mediterranean basin (Greece, Morocco, Spain, Italy and Turkey)..$^{10}$ However, the Mediterranean region is recognized worldwide as producing the best quality of saffron, which is attributed to many factors. ${ }^{10-11}$

However, up to date no studies have been carried out on the endophytic fungi of Moroccan saffron. At the international level studies focused on endophytic fungi recovered from corms and stems of saffron, but to our knowledge no study has looked at the roots that are the entry point for endophytic fungi. ${ }^{12-13}$ In this context our main objective was the isolation of endophytic fungi from roots of saffron growing in Morocco, their molecular identification and assessment of their possible antibacterial and antioxidant activities through the extraction of secondary metabolites.

\section{MATERIAL AND METHODS}

\section{Study area, plant sampling and endophytic fungi isolation}

Plant samples of C. sativus were collected randomly during April 2016

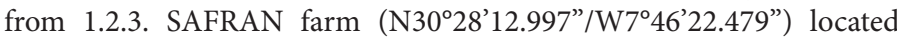
in Talakhat-Taliouine zone at Taroudant province, Souss-Massa region (Morocco). Root samples were separated from individual healthy plants. Each root sample was washed thoroughly under running tap water to remove soil particles, dried and cut into $1 \mathrm{~cm}$ length segments. The root segments were surface sterilized following the protocol of Fernández Di Pardo, ${ }^{13}$ then placed in Petri dish plates containing potato dextrose agar (PDA) and incubated in the dark at $25 \pm 2^{\circ} \mathrm{C}$ until fungal growth appeared.

\section{Molecular identification of endophytic fungi}

A lyophilized sample of fungal hyphae $(0.2 \mathrm{~g})$ was powdered in a Mixer Mill for $10 \mathrm{~min}$. DNA isolation was performed using the Promega ${ }^{\text {tx }}$ Wizard $^{\text {tw }}$ Genomic DNA Purification Kit according to the manufacturer's protocol. The isolated DNA was dissolved in $50 \mu \mathrm{l}$ of the elution buffer. PCR reaction was performed using my Taq TMHS mix bioline kit and ITS1 (5' - TCCGATGGTGAACCTGCGG-3') as the forward primer and ITS4 (5' - TCCTCCGCTTATTGATATGC- $3^{\prime}$ ) as the reverse primer. The PCR program was carried as follows: initial denaturation at $95^{\circ} \mathrm{C}$ for 5 min followed by 35 cycles of a denaturation at $95^{\circ} \mathrm{C}$ for $1 \mathrm{~min}$, annealing at $56^{\circ} \mathrm{C}$ for $30 \mathrm{~s}$ and an extension at $72^{\circ} \mathrm{C}$ for $1 \mathrm{~min}$ then a final extension of $10 \mathrm{~min}$ at $72^{\circ} \mathrm{C} \cdot{ }^{14}$ Purified PCR products were sequenced using the universal primer ITS1 at Genoscreen (Lille, France). The sequences were corrected using BioEdit software and compared to the available databases deposited in the NCBI.

\section{Extraction of endophytic fungi secondary metabolites}

The fermentation broth of the different fungus species was prepared as explained by Barik. ${ }^{15}$ Metabolites were extracted using two organic solvents: EtOAc and $\mathrm{CHCl}_{3}$. Each filtrate was mixed with an equivalent volume of solvent and placed under stirring for $2 \mathrm{~h}$. The organic layer (EtOAc) was separated from the aqueous layer in the separating funnel, this is the EtOAc fraction. The $\mathrm{CHCl}_{3}$ fraction was also obtained using the same procedure. The collected organic phase was recovered and concentrated under pressure by evaporating the solvent using a rotary evaporator. ${ }^{16}$ Finally, the resultant compound was dissolved in methanol.

\section{Antimicrobial activity}

The endophytic fungi extracts were evaluated against six bacterial strains from the collection of the Microbiology and Molecular Biology team (Faculty of sciences, Rabat, Morocco). One Gram-positive Bacillus sp. strain and five Gram-negative strains belonging to different genera: Stenotrophomonas sp., Pseudomonas putida, Pantoea sp. and Luteibacter sp. and the reference strain Escherichia coli (DH5a). All bacterial suspensions were prepared in liquid medium, Escherichia coli was grown in Luria-Bertani (LB) medium for $20 \mathrm{~h}$ at $37^{\circ} \mathrm{C}$ while the other strains were grown in Tryptone Yeast (TY) medium for $20 \mathrm{~h}$ at $28^{\circ} \mathrm{C}$ until the stationary growth phase. Microbial suspensions were diluted with either LB or TY media to a final concentration of $10^{6} \mathrm{CFU} / \mathrm{ml}$. The antimicrobial test was carried out using the Agar Diffusion Method. ${ }^{17}$ Each microbial suspension was spread on the surface of the appropriate agar media. Sterilized Whatman paper discs of $7 \mathrm{~mm}$ diameter was deposited on the agar surface and $15 \mu \mathrm{l}$ of each extract was added on the top of the disc, then incubated at $37^{\circ} \mathrm{C} / 28^{\circ} \mathrm{C}$ for $24 \mathrm{~h}$. The antimicrobial activity was measured by the diameter of the inhibition zone. ${ }^{18}$

\section{Antioxidant activity}

The antioxidant activity of the extracts was measured by two methods;

\section{The DPPH method}

DPPH is a stable, nitrogen-centered free radical of a purplish color which fades to shades of yellow color in the presence of scavenging compounds (antioxidants). The absorbance measurement used to calculate the percentage of DPPH radical inhibition is proportional to the anti-radical power of the sample. To test the antioxidant activity of the extracts studied, $50 \mu \mathrm{l}$ of each endophytic fungus extract was mixed with $1.95 \mathrm{ml} \mathrm{DPPH}(0.025 \mathrm{~g} / \mathrm{l})$ and incubated in darkness at $37^{\circ} \mathrm{C}$ for $30 \mathrm{~min}$. The DPPH scavenging capacity of the sample was calculated using the equation adopted by Wang. ${ }^{19}$ Ascorbic acid (Asc A) was used as a positive control and all the tests were carried out in triplicate.

\section{The BCBT method}

The mixture of $\beta$-carotene linoleic acid was prepared as follows: $2 \mathrm{mg}$ $\beta$-carotene was dissolved in $1 \mathrm{ml}$ chloroform and $25 \mu \mathrm{l}$ of linoleic acid and $200 \mathrm{mg}$ of Tween 40 were added, then chloroform was completely evaporated using a vacuum evaporator at $40^{\circ} \mathrm{C}$ for $5 \mathrm{~min}$. Finally, $100 \mathrm{ml}$ of $\mathrm{H}_{2} \mathrm{O}_{2} 50 \mathrm{mM}$ was added while shaking vigorously. Five milliliters of this reaction mixture was dispensed into test tubes and $100 \mu \mathrm{l}$ of a prepared methanol extract of endophytic fungi were added and vortexed. The absorbance of the mixtures was measured at $470 \mathrm{~nm}$ immediately $(\mathrm{T}=0 \mathrm{~h})$, then the emulsion system was incubated at $50^{\circ} \mathrm{C}$ during $3 \mathrm{~h}$ to calculate the percentage (A\%) of antioxidant activity by using the equation mentioned in Liu. ${ }^{20}$ Butylhydroxytoluene (BHT) and methanol were used as positive and negative controls, respectively. The discoloration kinetics of the emulsion of each sample was measured using a spectrophotometer at $470 \mathrm{~nm}$ immediately after sample preparation $(\mathrm{T}=0 \mathrm{~h})$ and at $1 \mathrm{~h}, 2 \mathrm{~h}, 3 \mathrm{~h}, 24 \mathrm{~h}$, and $48 \mathrm{~h}$.

\section{Statistical analysis}

All parameters were statistically analyzed using XLSTAT program (Version 2014.5.03), with \one-way ANOVA and compared using Fisher's Least Significant Difference test with a 5\% probability threshold. 
Chamkhi, et al.: Saffron Endophytic Fungi as a Source of Bioactive Secondary Metabolites

\begin{tabular}{ccc}
\multicolumn{2}{l}{ Table 1: Accession numbers of endophytic fungi isolated from the roots of C. sativus } \\
\hline Fungal isolate & Fungus species & Accession number \\
\hline LMR568 & Rhizopus oryzae & KY042103 \\
LMR569 & Aspergillus fumigatiaffinis & KY042104 \\
LMR570 & Aspergillus niger & KY042105 \\
\hline
\end{tabular}

Table 2: Antibacterial activity of EtOAc and $\mathrm{CHCl}_{3}$ extracts of endophytic fungi isolated from the roots of $\mathrm{C}$. sativus

\begin{tabular}{|c|c|c|c|c|c|c|c|}
\hline \multirow[t]{2}{*}{ Extracts } & & \multicolumn{6}{|c|}{ Inhibition zone (mm) } \\
\hline & & \multicolumn{2}{|c|}{ Chloroform extracts } & \multicolumn{3}{|c|}{ Ethyl acetate extracts } & \multirow[b]{2}{*}{ Rhizopus oryzae } \\
\hline Endophytic fungi & Control & $\begin{array}{c}\text { Aspergillus } \\
\text { fumigatiaffinis }\end{array}$ & Aspergillus niger & Rhizopus oryzae & $\begin{array}{c}\text { Aspergillus } \\
\text { fumigatiaffinis }\end{array}$ & Aspergillus niger & \\
\hline Stenotrophomonas sp & $0 \pm 0^{f}$ & $12 \pm 0^{\mathrm{d}}$ & $0 \pm 0^{\mathrm{e}}$ & $20 \pm 0^{c}$ & $11.5 \pm 1.15^{\mathrm{d}, \mathrm{e}}$ & $11 \pm 0^{\mathrm{d}, \mathrm{e}}$ & $15.03 \pm 0.05^{\mathrm{c}}$ \\
\hline Escherichia coli & $0 \pm 0^{\mathrm{f}}$ & $0 \pm 0^{\mathrm{f}}$ & $0 \pm 0^{\mathrm{f}}$ & $11 \pm 0^{\mathrm{d}, \mathrm{e}}$ & $26 \pm 0^{\mathrm{a}}$ & $10 \pm 0^{\mathrm{e}}$ & $11 \pm 0^{\mathrm{d}, \mathrm{e}}$ \\
\hline Pseudomonas putida & $0 \pm 0^{\mathrm{f}}$ & $12 \pm 0^{\mathrm{d}}$ & $10 \pm 0^{\text {e }}$ & $23 \pm 0^{\mathrm{a}}$ & $0 \pm 0^{f}$ & $10 \pm 0^{\text {e }}$ & $12 \pm 0^{\mathrm{d}}$ \\
\hline Bacillus sp & $0 \pm 0^{\mathrm{f}}$ & $12 \pm 0^{\mathrm{d}}$ & $0 \pm 0^{\mathrm{f}}$ & $0 \pm 0^{f}$ & $12 \pm 0^{\mathrm{d}}$ & $10 \pm 0^{\text {e }}$ & $9 \pm 0^{\mathrm{e}}$ \\
\hline Pantoea sp & $0 \pm 0^{\mathrm{f}}$ & $12 \pm 0^{\mathrm{d}}$ & $10 \pm 0^{\text {e }}$ & $10 \pm 0^{\mathrm{e}}$ & $15 \pm 0^{c}$ & $10 \pm 0^{\text {e }}$ & $14 \pm 0^{c}$ \\
\hline Luteibacter sp & $0 \pm 0^{\mathrm{f}}$ & $10 \pm 0^{\mathrm{e}}$ & $0 \pm 0^{\mathrm{f}}$ & $22 \pm 0^{\mathrm{b}}$ & $11 \pm 0^{\mathrm{d}, \mathrm{e}}$ & $10 \pm 0^{\mathrm{e}}$ & $20 \pm 0^{\mathrm{b}}$ \\
\hline
\end{tabular}

Values with different letters differ significantly $(\mathrm{P}<0.05)$

\section{RESULTS}

\section{Isolation and molecular identification of isolated endophytic fungi}

Sixty pure fungal isolates were obtained from roots of saffron plants and their DNA was extracted, amplified and sequenced. Their ITS rDNA sequences were $99-100 \%$ identical to three fungal species. Rhizopus oryzae was the most abundant (93.54\%) followed by Aspergillus fumigatiaffinis (4.83\%) and Aspergillus niger (1.61\%). All sequences obtained in this study were submitted to NCBI data bank. Accession numbers of the three isolates used in this study are available in Table 1.

\section{Antimicrobial activity}

The effect of three endophytic fungi extracts against six different studied bacteria by the Agar Diffusion Method showed an interesting antibacterial activity (Table 2). Antibacterial effects of EtOAc solvent fraction extracts were superior to those of $\mathrm{CHCl}_{3}$ extracts, particularly the EtOAc extract of Rhizopus oryzae inhibited all bacteria tested. However, different levels of bacterial sensitivity were recorded from high to low, with Luteibacter sp. being the most sensitive followed by Stenotrophomonas sp., Pantoea sp., Pseudomonas putida, Escherichia coli and finally Bacillus sp. The EtOAc extract of Aspergillus niger also inhibited all tested strains with a similar zone of inhibition while the EtOAc extract of Aspergillus fumigatiaffinis inhibited almost all the strains tested except Pseudomonas putida which was more resistant, while the Escherichia coli strain was the most sensitive.

On the other hand, $\mathrm{CHCl}_{3}$ extract of Rhizopus oryzae inhibited all the Gram-negative strains tested while the Gram-positive strain Bacillus sp. was resistant. The $\mathrm{CHCl}_{3}$ extract of Aspergillus fumigatiaffinis inhibited all the bacteria except Escherichia coli, while the $\mathrm{CHCl}_{3}$ extract of Aspergillus niger was only efficient on Pseudomonas putida and Pantoea sp. strains.

\section{Antioxidant activity}

The DPPH tests

The calculated percentage of DPPH decolorization showed that the performance of EtOAc extract of Aspergillus niger was high but still lower as compared to the standard substance: ascorbic acid $(5 \mu \mathrm{g} / \mathrm{ml})$ (Asc A) (Figure 1). According to the inhibition percentage of DPPH, extracts of the endophytic fungi can be classified in a decreasing order: Aspergillus niger (EtOAc) > Rhizopus oryzae (EtOAc) > Rhizopus oryzae $\left(\mathrm{CHCl}_{3}\right)>$ Aspergillus fumigatiaffinis (EtOAc) $>$ Aspergillus fumigatiaffinis $\left(\mathrm{CHCl}_{3}\right)>$ Aspergillus niger $\left(\mathrm{CHCl}_{3}\right)$.

These results indicate that EtOAc fraction extracts has higher radical scavenging activities than $\mathrm{CHCl}_{3}$ fraction extracts.

\section{The BCBT test}

The bleaching kinetics of $\beta$-carotene of the studied extracts were measured spectrophotometrically following the fading of the $\beta$-carotene at $470 \mathrm{~nm}$ during $48 \mathrm{~h}$ (Figure 2).

The $\beta$-carotene undergoes rapid discoloration in the absence of an antioxidant, the negative control, followed by Aspergillus fumigatiaffinis (EtOAc) and Aspergillus fumigatiaffinis $\left(\mathrm{CHCl}_{3}\right)$. At the opposite both Rhizopus oryzae extracts appear to be the best inhibitor of linoleic acid oxidation. The results of $\beta$-carotene bleaching measurements presented in Figure 3 confirmed that both extracts of Rhizopus oryzae have good antioxidant potentials, with $43.17 \% \pm 7.54 \mathrm{~b}$ and $42.82 \% \pm 4.04 \mathrm{~b}$ respectively, compared to the other endophytic fungi extracts.

\section{DISCUSSION}

In this study, 60 fungal isolates were purified from segments of $C$. sativus roots. The most abundant fungi species was Rhizopus oryzae followed by Aspergillus fumigatiaffinis and Aspergillus niger. Two recent studies reported the results about fungal endophytes associated with saffron corms and/or stems collected from different sites in Jammu and Kashmir State (India). ${ }^{21-22}$ The dominant endophytes in the first study were Rhizoctonia sp followed by Fusarium sp. and Phytophthora sp., ${ }^{21}$ while Phialophora mustea and Cadophora malorum. dominated in the second one. ${ }^{22}$ In a third study conducted in China only Penicillium vinaceum was isolated from corms of $C$. sativus growing in the Changxing Island. ${ }^{12}$ In our study the dominant endophytic fungi associated with saffron roots belonged to different genera and species than those reported in the previous studies. The striking differences in community composition 


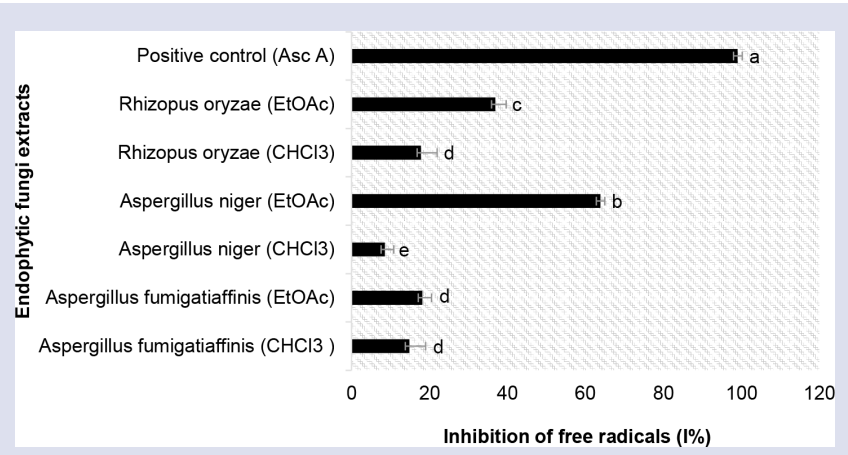

Figure 1: Antioxidant activity of EtOAC and $\mathrm{CHCl}_{3}$ extracts of endophytic fungi isolated from the roots of $C$. sativus evaluated by the DPPH method. Data expressed as means \pm standard deviation. Values with different letters differ significantly $(P<0.05)$.

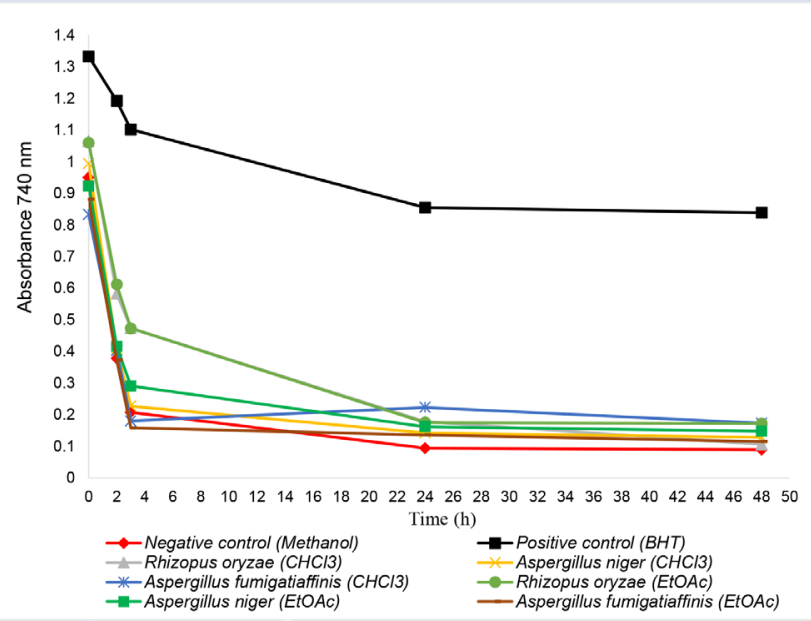

Figure 2: Kinetics of the inhibition of $\beta$-carotene oxidation by EtOAc and $\mathrm{CHCl}_{3}$ extracts of saffron endophytic fungi during the $48 \mathrm{~h}$ interval.

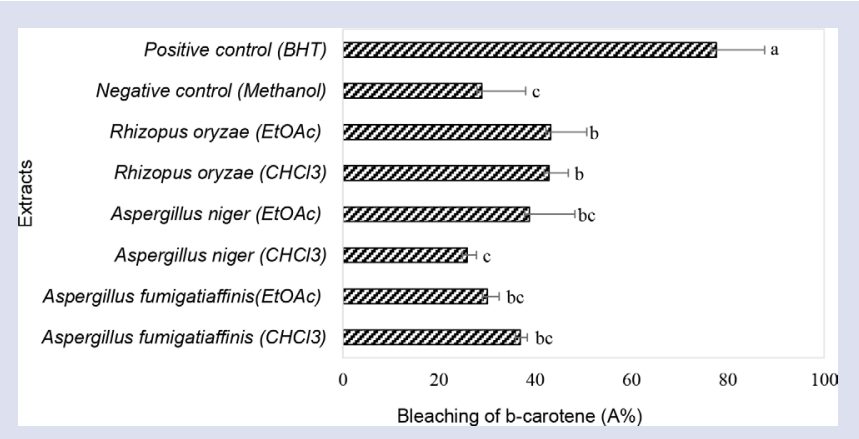

Figure 3: Antioxidant activity of EtOAc and $\mathrm{CHCl}_{3}$ extracts of endophytic fungi isolated from saffron roots evaluated by the BCBT method. Data expressed as means \pm standard deviation. Values with different letters differ significantly $(P<0.05)$. can be explained by the different organs examined in the different studies and/or by differences in the environment of studied areas that might harbor different fungi-saffron plants associations. These facts may also suggest that the degree of endophytic colonization reflect the degree of adaptation of the host to the biotic (potential mycobiota) and the abiotic (climate, etc) conditions of the site. ${ }^{23}$

Endophytic fungi from medicinal plants are important regarding their ability to produce a variety of bioactive compounds possibly those produced by their host plant. ${ }^{24}$ In this study, we investigated the antioxidant and antibacterial capacity of saffron endophytic fungi extracts. The five Gram-negative and one Gram-positive bacteria tested were highly sensitive to the extracts of the three endophytic fungi tested. The extract of Rhizopus oryzae was the most bactericidal followed by those of Aspergillus fumigatiaffinis and Aspergillus niger. Our results were consistent with those reported for Rhizopus sp. isolated from the medicinal plants Dendrobium devonianum and Dendrobium thyrsiflorum..$^{25}$ Other studies indicated that secondary metabolite compounds of Aspergillus fumigatiaffinis and Aspergillus niger possess antimicrobial activities. ${ }^{26-27}$ The bioactive compounds of fungal endophytes tested showed an antibacterial effect against Gram-negative species despite the complex structure and arrangement of their cell wall compared to the Grampositive bacteria. ${ }^{28}$ This effect is probably due to the large number of bioactive compounds that can be found in endophytic fungi extracts exhibiting antibacterial activity such as chaetoglobosins $\mathrm{A}$ and $\mathrm{C}$, pyrrocidines $\mathrm{A}$ and $\mathrm{B}$, ergosterol and $5 a, 8 \alpha$-epidioxyergosterol, pestalachloride A and B, 3-O-methylalaternin and altersolanol A. ${ }^{29}$

Overall, the results showed that the antioxidant activity varies depending on the type of the test used. In the DPPH method, Aspergillus niger extract showed the highest antioxidant activity while it was Rhizopus oryzae extract in the BCBT method. The absence of significant correlation between the results obtained with both methods can be explained by the fact that the antioxidant activity can involve various mechanisms and different parameters. ${ }^{30}$ Noting that DPPH method is the most known for the evaluation of free radical-scavenging activity because it is sample polarity-independent, very rapid, simple and reproducible. ${ }^{31}$ Discrepancies between the two methods cannot affect the recognized efficacy of the bioactive antioxidant components of the endophytic fungi especially those of Aspergillus niger ${ }^{26}$ and Rhizopus oryzae..$^{32}$

On the other hand, the nature of the solvent used in the extraction process is crucial. In our study ethyl-acetate extracts exhibited the highest antioxidant activity. This result may be explained by the fact that the active components are not well dissolved out of the extracts when using chloroform as solvent, or and if so, a very small quantity is being extracted out which gives little or no effectivity. Another possibility is that the bioactive components have a polarity which is best extracted out by ethyl acetate among the solvent fractions. ${ }^{33}$

\section{CONCLUSION}

In summary, roots of C. sativus collected from Taliouine in the south of Morocco harbor at least three species of endophytic fungi that possess not only an antibacterial activity against different bacteria tested but also an antioxidant activity. Our results suggest that the fungal endophytes of C. sativus could be an appropriate source of bioactive secondary metabolites.

\section{CONFLICT OF INTEREST}

There are no conflicts of interest. 


\section{ABBREVIATIONS}

PDA: Potato dextrose agar; PDB: Potato dextrose broth; LB: LuriaBertani; TY: Tryptone Yeast; CFU: colony forming unit; EtOAc: Ethyl acetate; CHCl3: Chloroform; ITS: Internal transcribed spacer; DPPH: $\alpha$,a-diphenyl- $\beta$-picrylhydrazyl; BCBT: $\beta$-Carotene bleaching test; Asc A: Ascorbic acid; BHT: butylhydroxytoluene; NCBI: National Center for Biotechnology Information.

\section{REFERENCES}

1. Lu H, Zou WX, Meng JC, Hu J, Tan RX. New bioactive metabolites produced by Colletotrichum sp., an endophytic fungus in Artemisia annua. Plant Sci. 2000;151(1):67-73

2. Yang $X$, Strobel G, Stierle A, Hess WM, Lee J, Clardy J. A fungal endophyte-tree relationship: Phoma sp. in Taxus wallachiana. Plant Sci. 1994;102(1):1-9.

3. Vega FE, Posada F, Catherine Aime M, Pava-Ripoll M, Infante F, Rehner SA. Entomopathogenic fungal endophytes. Biol Control. 2008;46(1):72-82.

4. Priti V, Ramesha BT, Singh S, Ravikanth G, Ganeshaiah KN, Suryanarayanan TS, et al. How promising are endophytic fungi as alternative sources of plant secondary metabolites. Curr Sci. 2009;97(4):477-8.

5. Rodriguez RJ, White JF, Arnold AE, Redman RS. Fungal endophytes: diversity and functional roles. New Phytol. 2009;182(2):314-30.

6. Mishra M, Prasad R, Varma A. Endophytic fungi: biodiversity and functions. Int J Pharm Bio Sci. 2015;6(1):18-36.

7. Huang WY, Cai YZ, Hyde KD, Corke H, Sun M. Biodiversity of endophytic fungi associated with 29 traditional Chinese medicinal plants. 2008 [cited 2018 Feb 15]; Available from: http://hub.hku.hk/handle/10722/60713

8. Gresta F, Lombardo GM, Siracusa L, Ruberto G. Saffron, an alternative crop for sustainable agricultural systems. A review. Agron Sustain Dev. 2008;28(1):95-112.

9. Bukhari SI, Manzoor M, Dhar MK. A comprehensive review of the pharmacological potential of Crocus sativus and its bioactive apocarotenoids. Biomed Pharmacother. 2018;98:733-45.

10. Gresta F, Lombardo GM, Siracusa L, Ruberto G. Effect of mother corm dimension and sowing time on stigma yield, daughter corms and qualitative aspects of saffron (Crocus sativus L.) in a Mediterranean environment. J Sci Food Agric. 2008;88(77):1144-50.

11. Lage $M$, Cantrell CL. Quantification of saffron (Crocus sativus L.) metabolites crocins, picrocrocin and safranal for quality determination of the spice grown under different environmental Moroccan conditions. Sci Hortic. 2009;121(3): 366-73.

12. Zheng CJ, Li L, Zou J, Han T, Qin LP. Identification of a quinazoline alkaloid produced by Penicillium vinaceum, an endophytic fungus from Crocus sativus. Pharm Biol. 2012;50(2):129-33.

13. Fernández DPA, Chiocchio MV, Barrera V, Colombo RP, Martinez AE, Gasoni L, et al. Mycorrhizal fungi isolated from native terrestrial orchids of pristine regions in Córdoba (Argentina). Rev Biol Trop. 2015;63(1):275-83.

14. Xu L, Zhou L, Zhao J, Li J, Li X, Wang J. Fungal endophytes from Dioscorea zingiberensis rhizomes and their antibacterial activity. Lett Appl Microbiol. 2008;46(1):68-72.

15. Barik BP, Tayung K, Jagadev PN, Dutta SK. Phylogenetic placement of an endophytic fungus Fusarium oxysporum isolated from Acorus calamus rhizomes with antimicrobial activity. EJBS. 2010;2(1):8-16.

16. Mohanta J, Tayung K, Mohapatra UB. Antimicrobial potentials of endophytic fungi inhabiting three ethno-medicinal plants of Similipal Biosphere Reserve, India. Internet J Microbiol. 2008;5(2)
17. Artur SJ, Monache FD, Smania FA, Cuneo RS. Antibacterial activity of steroidal Compounds isolated from Ganoderma applanatum (Pers.) Pat. (Aphyllophoromycetideae) Fruit Body. IJM [Internet]. 1999 [cited 2018 Feb 16];1. Available from:http://www.dl.begellhouse.com/journals/708ae68d64b17c52,541026cc01 c467e3,6 d711 8b651c7a14.html

18. Oliveira DA, Salvador AA, Smânia A, Smânia EFA, Maraschin M, Ferreira SRS. Antimicrobial activity and composition profile of grape (Vitis vinifera) pomace extracts obtained by supercritical fluids. J Biotechnol. 2013;164(3):423-32.

19. Wang L, Qiu P, Long XF, Zhang S, Zeng ZG, Tian YQ. Comparative analysis of chemical constituents, antimicrobial and antioxidant activities of ethylacetate extracts of Polygonum cuspidatum and its endophytic actinomycete, Streptomyces sp. A0916. Chin J Nat Med. 2016;14(2):117-23.

20. Liu X, Dong M, Chen X, Jiang M, Lv X, Yan G. Antioxidant activity and phenolics of an endophytic Xylaria sp. from Ginkgo biloba. Food Chem. 2007;105(2):548-54.

21. Raj P, Khan SS, Modak M, Lone ZA, Rather SA, Yaqoob M. Biodiversity of endophytic fungi in saffron (Crocus sativus) and antimicrobial activity of their crude extract. Indo Am J Pharm Res. 2013;3:3702-13.

22. Wani ZA, Mirza DN, Arora P, Riyaz-Ul-Hassan S. Molecular phylogeny, diversity, community structure, and plant growth promoting properties of fungal endophytes associated with the corms of saffron plant: An insight into the microbiome of Crocus sativus Linn. Fungal Biol [Internet]. 2016 [cited 2016 Nov 3]; Available from: http://www.sciencedirect.com/science/article/pii/ S1878614616300964

23. Hata K, Futai K. Variation in fungal endophyte populations in needles of the genus Pinus. Can J Bot. 1996;74(1):103-14.

24. Jain P, Pundir RK. Diverse endophytic microflora of medicinal plants. In: PlantGrowth-Promoting Rhizobacteria (PGPR) and medicinal plants [Internet] Springer, Cham; 2015 [cited 2018 Feb 15]. p. 341-57. (Soil Biology). Available from: https://link.springer.com /chapter/10.1007/978-3-319-13401-7_17

25. Xing YM, Chen J, Cui JL, Chen XM, Guo SX. Antimicrobial activity and biodiversity of endophytic eungi in Dendrobium devonianum and Dendrobium thyrsiflorum from Vietman. Curr Microbiol. 2011;62(4):1218-24.

26. Zhang $H$, Tang $Y$, Ruan $C$, Bai $X$. Bioactive secondary metabolites from the endophytic Aspergillus genus. Rec Nat Prod. 2016;10(1):1-16.

27. Schuster E, Coleman N, Frisvad J, Dijck PV. On the safety of Aspergillus niger - a review. Appl Microbiol Biotechnol. 2002;59(4-5):426-35.

28. Lambert PA. Cellular impermeability and uptake of biocides and antibiotics in Gram-positive bacteria and mycobacteria. J Appl Microbiol. 2002;92 Suppl:46S-54S.

29. Bano N, Rizvi IF, Sharma N, Siddiqui MH, Kalim M, Khan A, et al. Production of bioactive secondary metabolites from endophytic fungi. IRJET [Internet]. 2016 [cited 2016 Nov 1];03. Available from: https://www.irjet.net/archives/N3/ i6/IRJET-V3I6343.pdf

30. Koleva II, VanbeekTA, Linssen JPH, Groot A, Evstatieva LN. Screening of plant extracts for Antioxidant Activity: a comparative study on three testing methods. Phytochem Anal. 2002;13(1):8-17.

31. Kartal N, Sokmen M, Tepe B, Daferera D, Polissiou M, Sokmen A. Investigation of the antioxidant properties of Ferula orientalis L. using a suitable extraction procedure. Food Chem. 2007;100(2):584-9.

32. Peeran FM, Prasad L, Kamil D. Characterization of secondary metabolites from Rhizopus oryzae and its effect on plant pathogens. Int J Curr Microbiol Appl Sci. 2018;7(3):705-10.

33. Ogundare AO, Adetuyi FC, Akinyosoye FA. Antimicrobial activities of Vernonia tenoreana. Afr J Biotechnol [Internet]. 2006 [cited 2018 Feb 11];5. Available from: https://www.ajol. info/index.php/ajb/article/view/55815

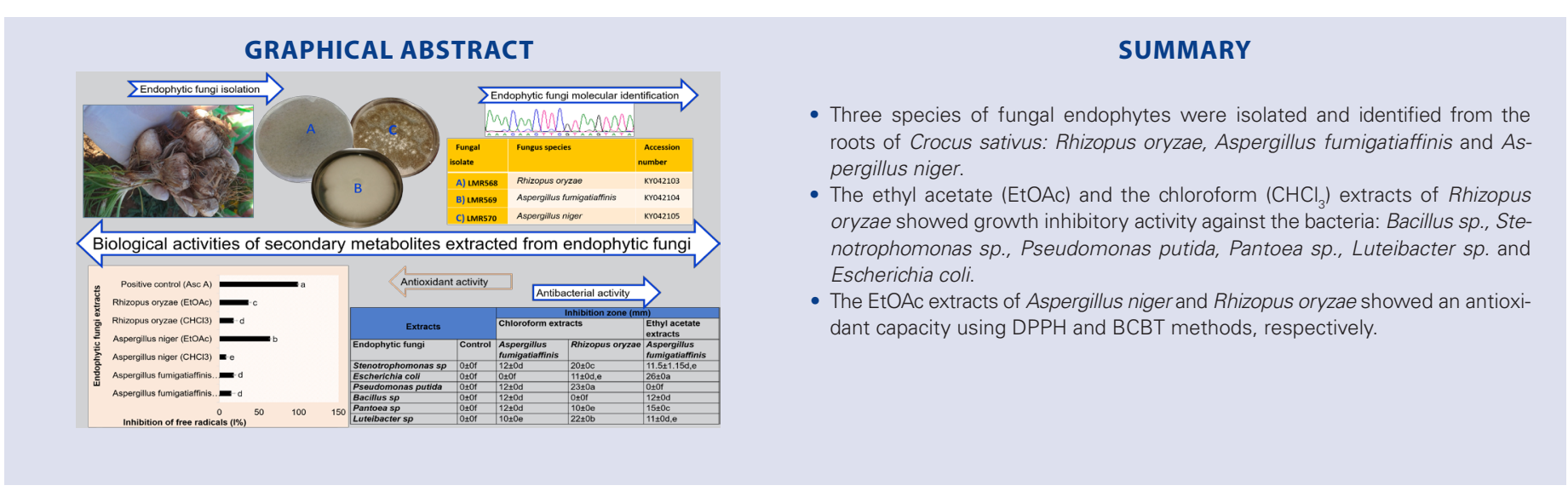




\section{ABOUT AUTHORS}

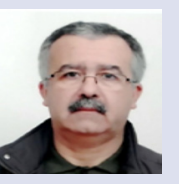

Dr. Jamal Aurag is a professor of microbiology since 1984 and director of the Center of Plant and Microbial Biotechnology, Biodiversity and Environment at the Mohammed V University in Rabat. He obtained his PhD "Doctorat d'Etat" degree in Microbiology in 1996 and a "diplôme d'études supérieures" degree in 1984 in Microbial Ecology from Mohammed V University in Rabat.

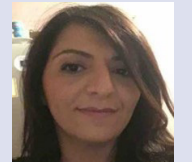

Dr. Laila Sbabou is a Research professor of Genomics and Biotechnology at MohammedV University of Rabat. She defended her national doctoral thesis in 2009 in Genomics and Biotechnology at the Faculty of Sciences of Rabat. She is a member of the Bureau of the Moroccan Association of Microbiology (AMM), the Moroccan Association of Biosafety and Biosecurity (AMBS) and the Moroccan Academy of Young Scientists (AMJS).

Imane Chamkhi is a Ph.D. student in the Microbiology and Molecular Biology Team, Center of Plant and Microbial Biotechnologies, Biodiversity and Environment, Faculty of Sciences, Mohammed V University in Rabat, Morocco. She obtained her master's degree in 'Plant Production'. A former head of the analytical laboratory of saffron quality at "1.2.3 SAFRAN" society, Taliouine, Morocco.

Cite this article: Chamkhi I, Sbabou L, Aurag J. Endophytic Fungi Isolated from Crocus sativus L. (Saffron) as a Source of Bioactive Secondary Metabolites. Pharmacog J. 2018;10(6):1143-8. 